\title{
Fruits of Education: E-technology and applications in lab animal training
}

\author{
Bruce W. Kennedy
}

Each of us learns in our own unique way. Approaches to learning include hands-on exercises, listening, reading, interpreting, repeated exposures to curriculum, working in groups, and more. In some cases the learning is content-focused, meaning the instructor determines which basic facts must be mastered and remembered; in others, what is learned is determined by the student, based upon individual needs or experiences. All are valid, but not all can necessarily be provided in busy and/or small training programs, primarily because of resource limitations.

Well, e-learning products can help to overcome some of that. Here I share some e-learning applications deemed pretty darn good by fellow trainers. An investment to learn them can return many benefits, because I predict the future of lab animal training will increasingly incorporate such technology. Each product has a free version as well as a paid one that includes extra features:

Poll Everywhere (www.polleverywhere. com). I have reviewed my experiences in greater detail in a previous issue (Lab Anim. (NY) 43, 291; 2014), but in short, it's a good piece of software for engaging everyone in a learning situation-whether in a classroom or at a conference. Poll Everywhere allows the trainer or teacher to pose questions for their students to answer with either their smart phones or computers; the app then provides summaries of the responses. Since writing about it, I have seen others like Jim Cox of Janelia Research Campus poll audiences at PRIM\&R, LAMA, AALAS, and ILAM.

Padlet (www.Padlet.com). Similar to Poll Everywhere, Padlet provides immediate engagement with the audience but with an extra feature that allows images to be uploaded as well as text. I have used it to facilitate PowerPoint presentations. For example, groups of students could be given 10 minutes to research a problem, such as why a particular species serves as a good model. They design and then post their slide(s) to Padlet, followed by an oral interpretation. The Padlet site is encrypted and runs on iOS and Android mobile devices as well as desktops.

PowToon (www.PowToon.com). This product builds animated training. Trainers can use preset materials or upload their own to tailor their presentation. I have created basic training videos within a few hours. Luis Zorrilla at the University of Texas at San Antonio shared with me that sending a PowToon cartoon link as training content in an email-instead of text and attachments-to investigators has improved reading rates to $80 \%$ and has resulted in smoother transition to administrative changes.

Kahoot (https://getkahoot.com). From their website, "Kahoot! is a game-based blended learning platform, allowing both educators and students to research, create, collaborate and share knowledge." After a lesson or as a pre-test to a training session, the quiz style of Kahoot helps teams to learn together. Summer Boyd, a trainer at Baylor College of Medicine, uses it to engage learners with real-time questions and a little competition. It also allows the instructor to gauge how the material they are delivering is being perceived. If the learners are not answering correctly, a discussion can immediately address questions that some people may not feel comfortable asking in a group setting.

Nearpod (www.nearpod.com). This software is perhaps the Skype of training, but it also has an established science curriculum. Using a portable device, a person training others can walk through an environment and describe what is being seen in real time. Virtual field trips! Imagine an ABSL3 or 4 facility-to bring a class in would be a challenge in terms of PPE resources and health exposures, but Nearpod allows a trainer with an iPad or other device to show off the facility to anyone viewing. Boyd uses a similar product called Periscope (www. periscope.com), which allows for real-time video recording, much like FaceTime or Skype. The participants are not able to verbally comment during the video but they can text in. The video stays up for 24 hours and can be public or private depending on the material and the audience.

EDpuzzle (www.edpuzzle.com). With EDpuzzle, a trainer can select a video, select the most pertinent parts, assign it to be watched, and insert quiz questions to assess learning. When I searched "vet tech" and "mouse handling" in its database, more than 100 videos for each popped up. As one review site (http://www.edudemic. com/edpuzzle-review-easy-use-toollets-teachers-quickly-turn-online-videolessons/) said, it works "to make sure that online video assignments are actually being watched and that students are grasping the concepts and information being presented." This resonates with my need-toknow, good-to-know, and fun-to-know approach to teaching.

QR code. In training sessions, it might be easier to use a Quick Response Code instead of a long and hard-to-read address (URL) to get participants to a website quickly. Tiny URLs (www.tinyURL.com) work well for that, too, greatly shortening long addresses.

Hopefully, getting to know these products will facilitate your understanding of the changing role of technology and enhance teaching, training and learning. 